\title{
The Ecological Research and Analysis of Environmental Art Design
}

\author{
haijiao Xu \\ Jilin business and technology college \\ 346591653@163.com
}

Keywords: Environmental Project,Artistic Designing,Ecological, Research and Analysis

\begin{abstract}
From 21th century, with the continuous development of economy and promotion of living standard of people in China, the environmental problem and resource shortage,caused by industrial development appears gradually. In this context, the ecological idea of environmental art design starts to be popular with people. Based on the expounding of basic conception and development tendency of environmental art design, this text studied and solved out the problems in ecological development, and gave the coping approach.
\end{abstract}

\section{Introduction}

There is great diversity, which results to different demands of people for surroundings in material life, therefore, the objects of environmental art different. There are lots of contents in environmental art design, including urban planning and indoor planning. Based on the demands of people, the environmental art design needs the support of science and technology, and the fusion with artistic sense. The basic of environmental project is environmental art design, which aims at integrating human wisdom in nature. It refines and distills the natural beauty as well as make people feel the power of design.

\section{The Basic Meanings and Contents of Environmental Art}

The Basic Meanings of Environmental Art. Environment has wild connection,which not only includes the work of art, designed for beautifying environment,but also happening art, land art and landscape art, etc. It also explained that all the things people saw are the factors of environment. Plants and trees in nature, buildings, equipments,and advertisements made by people,the clothes people wear, and the lifestyle of relaxation and sports are all scenes in environment. Under the specific condition of life and nature, and based on the relevant engineering technology, law of nature and artistic rule ,environmental art can create integrated spacial art, which can meet the demands of life and survival and the aesthetic rules. It includes two contents, one is to meet the aesthetic rules and the other is to meet the necessity of survival, both of which explore the environment for beauty creating while understanding and researching their demands.

The Substance of Environmental Art Design. Environmental art design , whose goal is to provide a reasonable and comfortable spacial place for people's life, work, and study, can be thought as the plan and design of internal environment of constructions based on art. The environmental art design is a general performance of many subjects. In practical creation and design,an ecologically substantial design concept can emerge if ecological problems are kept an eye on as well as other science and technology are developed. 
Artistic Tendency. Art comes from life,which here means the most original and essential life of people. The design of ecological art can not only furthest restore the essence of life, but meet the pursuance of environmental art design.

Emotional Tendency. The fast pace of life brings physical resources as well as lots of pressure to people. The pressure of the people who live in steel and concrete cities grow with each passing day. These pressure will do harm to people mentally and physically if can't be dispatched properly. While under great pressure, most people want an environment to release pressure and to adjust their nervous mood, for the hope of which the ecological environmental art design generates. The ecological environmental art design follows the social trend, because it's humanized, and in this environment people can feel fusing with nature and release their unhealthy emotions.

Social Tendency. The harmonious coexistence of people and nature is not only the demand of harmonious society development and the demand of social sustainable development of people,meanwhile, it's the pursuance of environmental art design. They have the same goal. At present, cities are all the world of armored concrete, but the development of society request us to change this lifestyle. As a result, people start protecting the environment rather than remaking. The ecological environmental art design meets the development requirements of harmonious society, so the development of ecological environmental art design fits for social development tendency in China.

\section{The Problems in the Ecologic Tendency of Development of Environmental Art Design}

The Serious Inhibition of Localization. Because the environmental art design in China starts relatively late, the bringism happens inevitably. However, the local culture of China will be restrained if bringism can't be effectively controlled. The key point of ecological development is to realize sustainable development in a region, whose demand is the combination of humanity and nature. However, the frequent use of bringism without the consideration of physical truth and their differences can't realize the harmonious development of human and nature. China has a long history, during which there were lots of valuable experience, and creates lots of spirits and culture with Chinese characteristics. Therefore, the lack of local culture will restrain the sustainable development.

The Havoc of Eco-Traditional Architecture. The continuous development of urbanization usually sacrifices the design of eco-traditional architecture, in which sense the ecological development will be restrained. Arcology, which usually distributes in the urban and rural junction or the country, is the result of combination of human's custom and geographical conditions during the regional social development. It also effectively responds to regional cultural ecology. However, with the increase of concrete steel building, the eco-traditional architecture has been damaged severely,thus leading to the damage of regional natural ecology. The economic development sacrifices the environment.

The Excessive Participation of Consumerism. With the gradual increase of the living standard of people, the consumerism, which existed in the upper class, develops into ordinary people. The increase of consumer demand increase the market transaction. With the deepening of consumption consciousness, the pressure faced by environment and resources gradually increased. To meet the demands of consumers, the environmental art design has to sacrifice environment. Abnormal consumption view and environmental art design aren't valued by the country, leading to the distortion of development direction. At this stage, all the western developed countries take steps to restrain the guide level of environmental art design caused by inflated consumption. However, it's still blank in China. 


\section{The Ecological Strategy of Environmental Art Design}

Social Design Strategy. Social design strategy of environmental art design refers to those in which designers follow sociality and ecology and don't blindly pursue artistry. At present,the environmental conditions isn't optimistic, considering which, designers should focus on present lifestyle and cultural pattern and create works that can satisfy the demands of people under present circumstance rather than blindly sacrificing environment. In modern society, some designers ignore the environmental conditions to pursue artistic effect. Although the artistic effect of their works are praiseworthy, the damage to environment is irreparable. It's unblamable for designers to pursue artistry, but the blind pursuing of art is inadvisable and unsuited for present development tendency of environment. In nowadays society, people pursue the art form with the balance and harmony between human and nature, which can not only realize the design objective of designers, but can protect the environment in the long run. The design will be popular with more people, if our designers can fuse design into environment rather than sacrifice environment. Now, many companies and TV station use lots of illumination for activity results. Although the beautiful light effect carried praise of people, the waste of power resource should not be ignored.

Safety Design Strategy. The safety design strategy of ecological environmental art design includes two aspects, safety of people and safety of nature. As for safety of people, environmental art design aims at meeting people's demands and enhancing their living quality. Therefore,safety of people is the first-oriented. The works, in which there are security hole, are unqualified. For example, security of people should be fully considered while waterscape being designed. There should be guardrail and warning sign set beside a fountain to prevent playful children from falling into water. Meanwhile, the waterscape like fountain should not be so deep that will drown the people falling into water. As for natural security,the designers should consider surroundings and the chose proper resources while designing. On the premise of fusion with environment,the basis of proper modeling is fastness, and the materials should be convenient for recycling and disassembly. For example, in the design of district environment, because of space limitation, some landscapes are designed overlapping with parking space, which threatens the security of children playing there. There are many other potential safety hazard left for the lack of consideration. The designers are not only responsible for design but also for the security of audiences, therefore, the designers should consider the safety of works.

Comfortable Design Strategy. The environmental design is made for providing more comfortable living and working environment and satisfying people's needs. The quality of lighting materials of good environmental art design should be higher than those in daily life. On the spiritual plane, the design should be relaxing and rich people's aesthetics. For example, the purpose of design of Find Horn, the ecological village in the north of Scotland is fusing comfortable life with environmental protection. The designers mostly use glass material and install solar power system to assure the effective illuminations. The building materials are all environmental protection materials which are non-toxic and harmless. The thickened roof and wall can reduce air condition usage in summer as it can store air conditioning, and keep warm as well as saving coal resources in winter. In addition, there also is wind power system here, which can not only satisfy the artistic pursuit, but also maximize the resource utilization. Therefore, it can't only make people's life more comfortable, but also is environmental protection and energy saving, for it combined the environmental protection with social construction.

\section{The Application of Ecological Idea in Environmental Art Design}


The Extending of Function and Usage. There are many abandoned buildings and facilities around us, which can't satisfy the previous needs of people, but has other value which need to be explored through natural and cultural environment. For example, 789 Arts District in Chaoyang District, Beijing City were old abandoned industrial factory district owned by state before literary organizations and artists' coming. And now, after the large-scale rent and modification, they have developed into arts center,studios, galleries and even companies with international SOHO art settlement and LOFT lifestyle. It's thus clear that the primary cause of success of 798 Arts District is the exploration of potential of old buildings and facilities, which not only developed the new application value, but reduced environmental disruption caused by large-scale demolition. The extending of this function is the model which successfully adds ecological idea into environmental art design.

The Recycle of Energy Substance. The utilization of recycled materials has been an important ecological idea concerned by all walks of life. At present, with the continuous development of science and technology,there are many classic cases about recycling. For example, in the design of some buildings, they were added rainwater recycling system and decontamination plant to reuse the recycled water. The recycling of water can not only reduce the cost of water, but also reduce the dependence of town house on water system. In the ecological aspect, it can also effectively protect local water resource. In particular, the recycling should be enforceable and be enforced after specific research, or it will cause the wasting of resource unnecessarily.

Promoting to Restore the Balance of Ecological. The application of ecological idea in environmental art aims at maintaining the ecological balance,including the balance between man and nature, and between buildings and nature. Therefore, the local environmental attribute should be maturely considered and efficiently reflected in the environmental art design. For example, we should use local plants for landscaping in garden design. As for the design of landfill, we should consider the future development and promote ecological restoration of the district, which is not only the demand of artistic design, but also an important means for the harmonious coexistence of human and nature.

\section{Conclusion}

In recent years, with the continuous progress and development of technology and social survivability, people severely damage the environment while creating wealth. Environmental degradation and resource shortage have caused serious obstruction to social development. Therefore, it has been aspirations of people around the world to protect the environment, to realize the sustainable development and harmonious development between people and nature ,in which context, the ecological idea of environmental art design has become a popular idea fitting for the era development. The development of this idea made many requests to designers, namely, not just pursuing the artistry,but effectively reflecting the ecology. We need to satisfy the needs of people for comfortable life, as well as protecting the nature.

\section{References}

[1] Dai ShanShan. The Discussion about Modern Environmental Art Design under the View of Ecologic Civilization[J]. Sichuan Building Science. 2012(06)

[2] TangZiqian,Li Jingwen. The Analysis of Ecological Idea Based on Environmental Art Design[J]. Door\& Window. 2013(10) 
[3] Wen Jiangang. The Research of Sustainable Development Design Philosophy of City Image and Environmental Art [J]. Urban Planning. 2000(02)

[4] Liang Zhixiong. The Exploration about the Problems and Solution of Urban Center Planning [J]. China Science and Technology Information . 2005(16) 